\section{ECCOMAS}

Proceedia
COMPDYN 2021

$8^{\text {th }}$ ECCOMAS Thematic Conference on Computational Methods in Structural Dynamics and Earthquake Engineering M. Papadrakakis, M. Fragiadakis (eds.) Streamed from Athens, Greece, 28 - 30 June 2021

\title{
A SUSTAINABLE SOLUTION FOR THE SEISMIC STRENGTHENING OF RC EXISTING BUILDINGS THROUGH THE HPDF SYSTEM (HPDF): A CASE STUDY
}

\author{
Giuseppe Ventura, Vincenzo Manfredi, Angelo Masi, Giuseppe Santarsiero, \\ Andrea Digrisolo \\ School of Engineering, University of Basilicata \\ via dell'Ateneo Lucano, 10, Potenza, Italy \\ \{vincenzo.manfredi, giuseppe.santarsiero, angelo.masi, giuseppe.ventura, an- \\ drea.digrisolo\}@unibas.it;
}

\begin{abstract}
The large number of existing buildings for which seismic rehabilitation interventions are required highlights the need of sustainable techniques able to reduce costs and downtime. To this purpose, a new strengthening technique named High-Performance Dissipating Frame (HPDF) was developed. It consists of new framed structures applied from the outside thus reducing the impact and relocation needs of tenants. This is even more important for strategic (e.g. hospitals) and other public buildings (e.g. schools) due to the social and economic effects deriving from their interruption of use. HPDF system consists of external precast RC frames (i.e. exoskeletons) rigidly connected to the existing structure and equipped with both shear and flexural damper devices to provide a high dissipation capacity in case of seismic actions and then to protect existing building. In the paper, the HPDF system has been applied to a Reinforced Concrete (RC) school building designed only to gravity loads. After a brief description of the building under study and the HPDF system, the stiffness, strength, and dissipation properties have been determined using an iterative displacement-based design procedure purposely set up. Results show that the considered strengthening technique increases seismic performance of the existing building according to different targets involving both structural and non-structural components, also avoiding any other local intervention.
\end{abstract}

Keywords: Seismic Strengthening, Existing Buildings, RC Structures, Exoskeleton System, Energy Dissipation. 


\section{INTRODUCTION}

The large number of existing buildings in Italy without adequate seismic protection [1] requires the definition of sustainable intervention techniques, able to reduce time and costs, and to limit the interruption of use. Specifically, regarding existing reinforced concrete (RC) structures, most of the gap is due to inadequate detailing and poor behavior of fragile elements like beam-column joints [2] as clearly demonstrated by recent earthquakes [3].

Sustainable strengthening techniques were and are being developed, at both local and global level, within the activities of the Work Package 5 "Integrated and Sustainable Interventions for the Requalification of Existing Buildings" (WP5) carried out in the framework of the 2019-21 research program funded by the Italian Dept. of Civil Protection (DPC) and carried out by the Network of Laboratories of Earthquake Engineering (ReLUIS). Among others, a patented local seismic strengthening system was developed in order to allow cheap interventions only from the outside [4].

Also, new techniques were developed to perform upgrading interventions at global level as for example that based on $\mathrm{RC}$ exoskeletons $[5,6,7]$. This solution is frequently coupled with further interventions devoted to reducing energy consumption of buildings, thus increasing their sustainability $[8,9]$.

In [10] a strengthening solution based on the use of precast RC exoskeletons connected to the existing structure to provide it with additional seismic capacity, is proposed. Further, the possibility of adding dissipative capacity to this kind of intervention technique has been studied $[11,12]$, in order to enhance global performance and therefore optimize the required intervention costs. The strengthening solution named HPDF (High Performing Dissipation Frame) was developed in order to optimize the position of dissipative elements coinciding with the centreline of the beams. This makes it possible to maximise the deformation to which the dissipative elements are subjected, which is amplified with respect to the inter-storey displacement. Therefore, an increased effectiveness is expected with respect to dissipative bracing systems, where hysteretic dissipation elements work on the interstorey displacement due to seismic actions.

As a first step of the development process, the HPDF frames were applied to simple structural models [11] in order to identify the parameters that most influence their behaviour and effectiveness in increasing the seismic capacity of the structure under intervention. Moreover, the iterative design process was outlined starting from the push-over curve of the existing structure and the identification of the seismic capacity gap to be covered by the strengthening technique.

The present study, relying on the design method set-up in [11], is devoted to applying the strengthening solution to a real case study represented by the "Santini school building" located in the small town of Loro Piceno town, province of Macerata, Italy. The building is an old RC structure dating back to early ' 60 s designed only to gravity loads. The application of the HPDF system to a real case study is helpful in identifying the potential advantages and disadvantages of the technique and to better evaluate its effectiveness.

\section{DESCRIPTION OF THE STRENGTHENING SYSTEM}

As can be seen in Figure 1a, the HPDF system is made up of two main components each one made up of a column and a half beam. At the beam end, the shear dissipative devices are placed to work under the relative displacements (S hinges). Moreover, at the base of the column, flexural dissipative hinges are inserted working under the rotation of column members. It can be noted that when the span length is two times the interstorey height, the relative dis- 
placement of the $\mathrm{S}$ hinge is equal to $2 \Delta$, where $\Delta$ is the interstorey displacement. This highlights the advantage with respect to other devices whose dissipative capacity is related to the interstorey displacement $\Delta$ as, for example, in the case of bracing systems.

A suitable working mechanism of the HPDF system is obtained when the framing elements behave in a suitably stiff manner. In fact, in order to maximize the relative displacement of the $\mathrm{S}$ hinge, small or no deformations of the beam members are needed. This is strongly dependent on the bay length and makes the system not effectively applicable in case of large values of the span length, which would require large cross-sections of beams and columns. In these cases, an additional bracing system may be introduced to reduce RC members deformations thus increasing the effectiveness of the HPDF system (see Fig. 1b)

The new frames of the HPDF system have to be connected to the existing structure by means of shear connectors, grouted with epoxy resin and designed to resist the (inertial) shear forces that are transferred from the existing structure to the new frames. In order to allow the dissipative kinematics, the connections must be such that only vertical displacements are allowed.

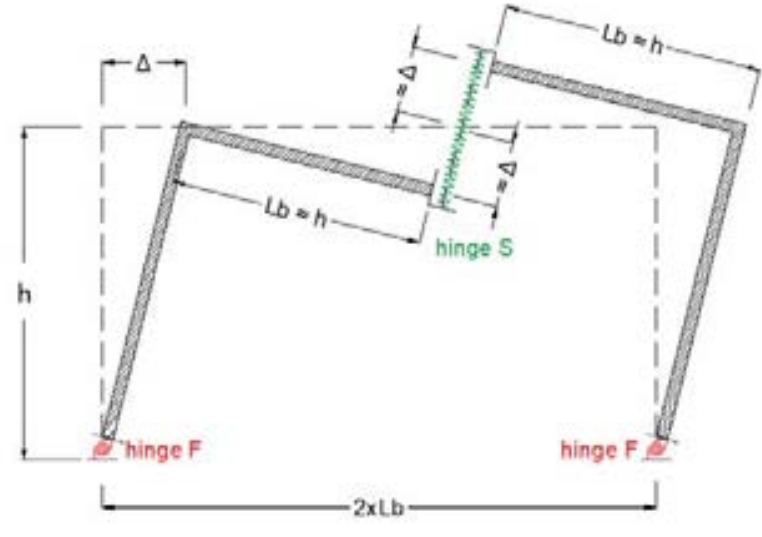

a)

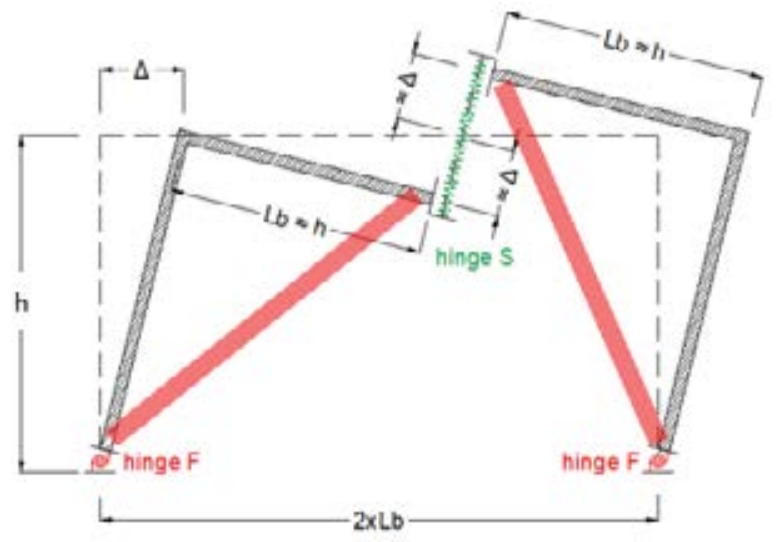

b)

Figure 1: Position of the bending (F) and shear (S) hinges for a single-bay frame a); HPDF system with addition bracing members b).

The connection between the HPDF system and the existing structure must be present only at beam column joints in order to allow a rigid body behavior of new frames with respect to the existing one. Details of the connection system are reported in [11].

\section{DESCRIPTION AND ASSESMENT OF THE CASE STUDY}

In order to apply a reinforcement technique from the outside, by means of an exoskeleton, the Primary School "Pietro Santini" (Fig. 2a) in Loro Piceno (Macerata) was selected as a case study. The building was damaged by the 2016-2017 Central Italy seismic sequence.

The school building has RC structure, rectangular plan with three stories (Fig. 2b), two of which are below the ground level (south side), while only one storey is visible on the north side, which faces the main road. The building has a floor area of about $400 \mathrm{~m}^{2}$ and it reaches a total height of about $12 \mathrm{~m}$. The structure has a regular mesh of columns, with the exception of a small plan irregularity. The structural arrangement shows the presence of a series of oneway frames (Fig. 2b). The staircase, made of two RC walls, is eccentric with respect to the building's center of mass. In order to verify the effectiveness of the proposed technique, the modelling activity first focused on the development and calibration of the FEM model of the building in SAP2000 for assessment purposes. 


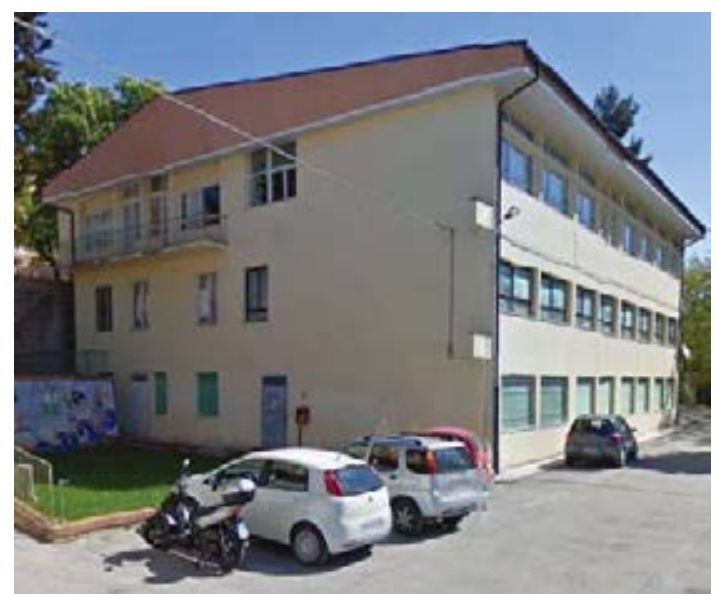

a)

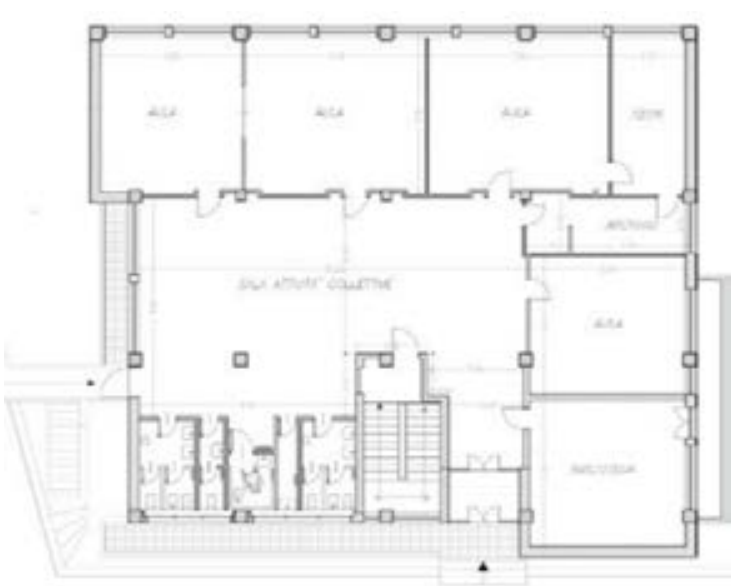

b)

Figure 2: The "Pietro Santini" school buildings case study in Loro Piceno: a) photo of building; b) floor plan.

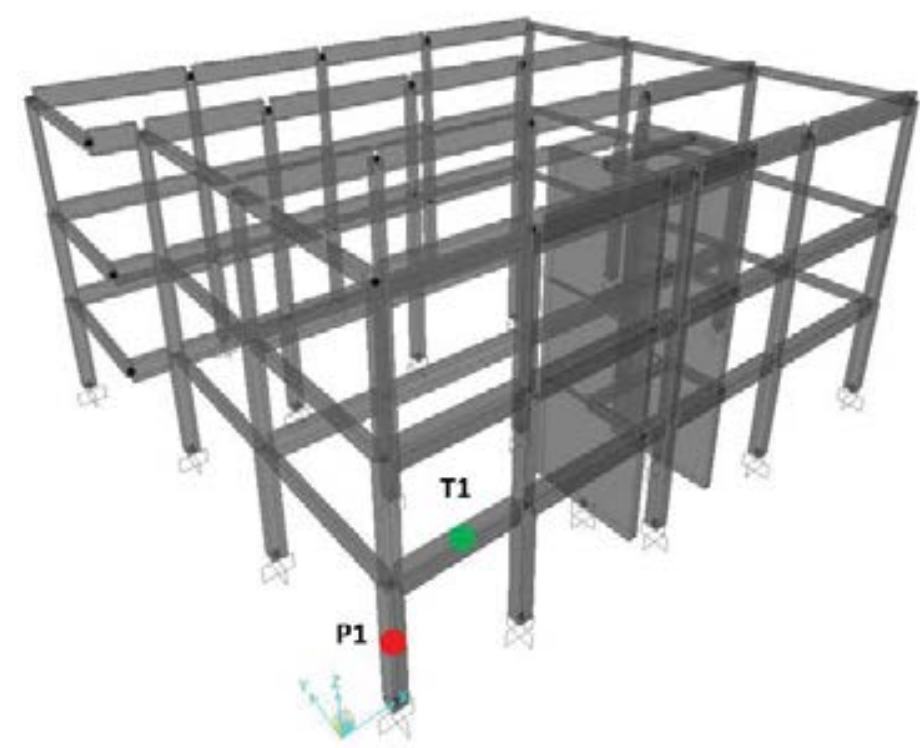

\begin{tabular}{cccc}
\hline Mode & Type & $\begin{array}{c}\text { T } \\
(\mathrm{sec} .)\end{array}$ & $\begin{array}{c}\text { Mass } \\
(\%)\end{array}$ \\
\hline 1 & Rotat. (z) & 0.81 & 50 \\
2 & Transl. (x) & 0.64 & 51 \\
3 & Transl. (y) & 0.41 & 73 \\
\hline
\end{tabular}

\begin{tabular}{cccc}
\hline \multicolumn{4}{c}{ Storey seismic masses } \\
\hline Storey & $\begin{array}{c}\text { Ux } \\
\text { [ton.] }\end{array}$ & $\begin{array}{c}\text { Uy } \\
\text { [ton.] }\end{array}$ & $\begin{array}{c}\mathrm{Rz} \\
{\left[\text { ton. }^{*}{ }^{2} \text { ] }\right.}\end{array}$ \\
\hline I & 452 & 452 & 38741 \\
II & 444 & 444 & 37893 \\
III & 472 & 472 & 40173 \\
\hline
\end{tabular}

Figure 3: 3D finite element model and dynamic characteristics of the structure.

The material properties were determined through destructive and non-destructive tests in accordance with the code NTC 2018 [13]. In particular, the mechanical characterisation of the compressive strength of concrete was obtained from compressive tests on cores drilled from the structure. From these tests a mean cylindrical compressive strength $\mathrm{f}_{\mathrm{cm}}=10.9 \mathrm{MPa}$ has been found. The yield strength of the reinforcing steel was obtained from tensile tests on reinforcement bars. These tests resulted in an average yield strength $f_{y m}=370 \mathrm{MPa}$. It is worth noting that the material properties found in the Santini school are essentially consistent with the expected values reported in [14] for the same construction period.

Figure 4 shows the reinforcement arrangement and moment-rotation relationships of typical column (Fig. 4a) and beam (Fig. 4b) members. The column cross-section dimension is generally 46x46 cm (related to column P1 in Fig. 3), while beams have 40x65 cm section (beam T1 in Fig. 3). 


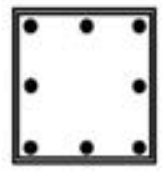

P1-45X45

Reinforcement

Rebars: $8 \phi 16$

Stirrups: $\phi 6 / 25$

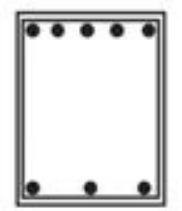

$\mathrm{T} 1-40 \times 65$

Top Reinforcement

Rebars: $5 \phi 16$

Bottom Reinforcement

Rebars: $3 \phi 16$

Stirrups: $\phi 8 / 10$

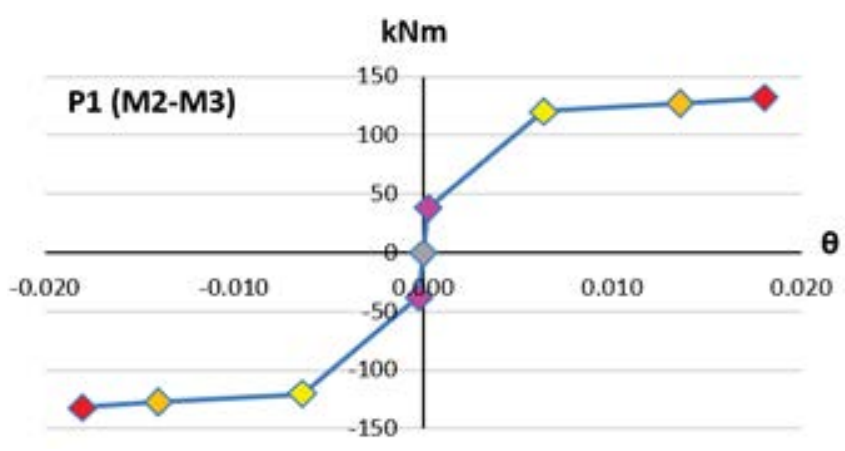

a)

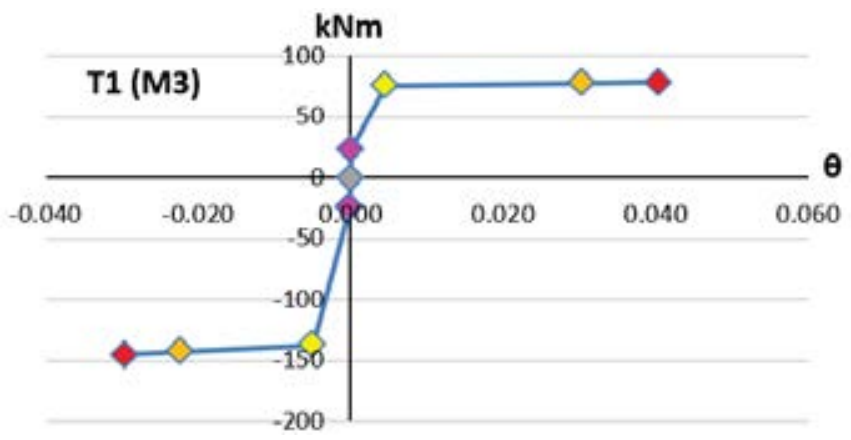

b)

Figure 4: Plastic hinge modelling of column (P1) and beam (T1).

Figure 5 shows the capacity curve of the structure, determined through push-over analysis in the $\mathrm{X}$ direction considering a pseudo-triangular eccentric load distribution. The analysis was pushed up to a displacement of $120 \mathrm{~mm}$ (evaluated at the top of the structure) where the seismic capacity/demand ratio is equal to $\zeta_{\mathrm{E}}=1$. The capacity curve does not account for possible brittle failures but only for ductile ones related to the exceedance of the rotation capacity of flexural hinges in RC members. The identification of brittle failures in RC members was made ex-post by comparing shear stresses on beams, columns and beam-column joints with the related capacity. Therefore, the displacement (and related base shear) that causes the first fragile crisis was determined equal to $\mathrm{d}=11 \mathrm{~mm}$ to which a $\zeta_{\mathrm{E}}=0.12$ is obtained.

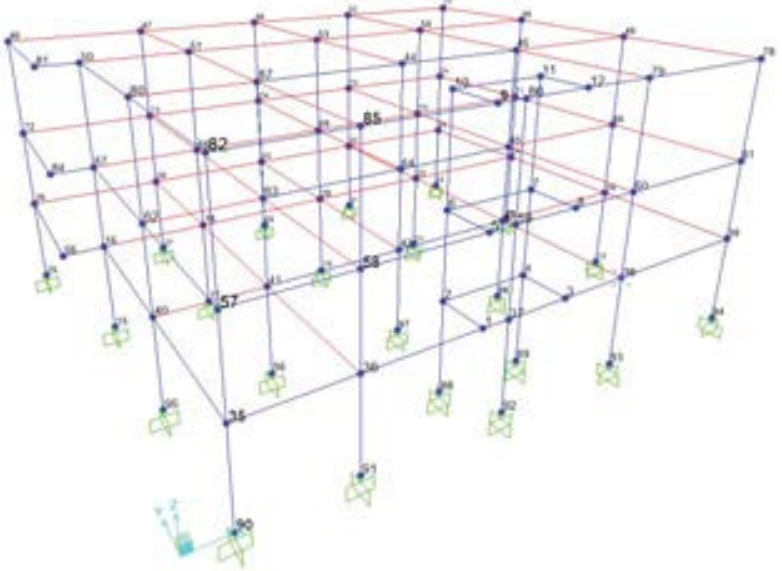

a)

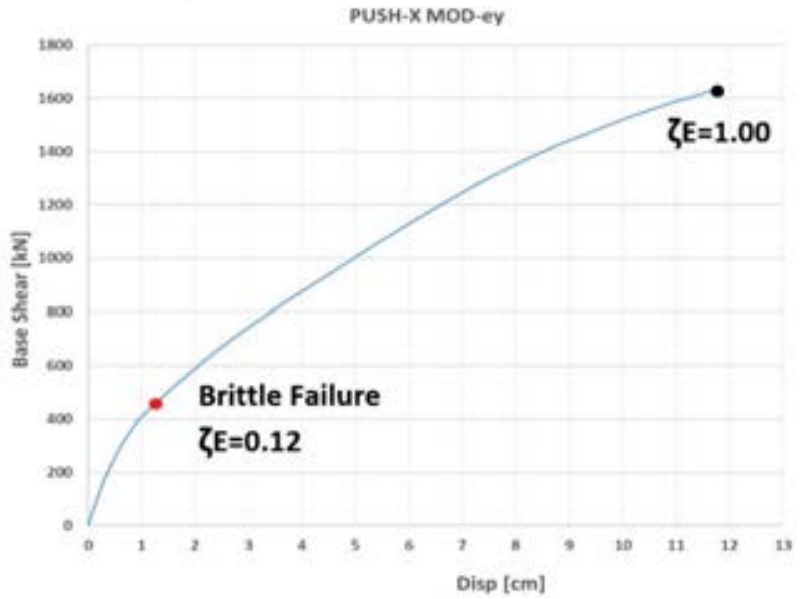

b)

Figure 5: Structural model a); Push-over analysis in the $\mathrm{X}$ direction b). 


\section{THE STRENGTHENING INTERVENTION}

In order to design the strengthening intervention, all the HPDF frame elements were considered as elastic and substantially rigid, while the dampers were modelled as elasto-plastic, without hardening behaviour. Starting from the push-over (PO) curve [15, 16], obtained for the X-direction (Fig. 5), the equivalent bilinear behaviour was reported in the ADRS format along with the 5\% damping demand spectrum, according to the current code NTC-2018 [13]. In the first design phase, the achievement of seismic upgrading (conventionally related to a value $\zeta_{\mathrm{E}}=0.6$ ) was set for the structure, therefore the demand spectrum was properly reduced. The target displacement was assumed to be equal to the displacement at which the existing structure achieves the first fragile collapse $(\mathrm{dy}, \mathrm{EX}=11 \mathrm{~mm} d y, \mathrm{EY}=13 \mathrm{~mm}$, for the $\mathrm{X}$ and Y directions respectively). This latter means that the HPDF system is designed to prevent any fragile collapse in the existing structure, in order to also avoid local interventions to strengthen RC members. The displacement value is reported on the demand spectrum to evaluate the stiffness value of the complete dissipative frame structure $\left(\mathrm{K}_{\mathrm{EX}}+\mathrm{HPDF}\right)$. The stiffness is given by the slope of the straight line connecting the origin of the ADRS plane and the intercept on the demand spectrum (Fig. 6). By reporting the target displacement on the reduced spectrum (damping $\xi=30 \%$ ), both the force and the yield displacement of the HPDF-frame reinforced structure are determined. In this case the ductility demand is approximately equal to 2.0.

After defining the $\mathrm{K}_{\mathrm{EX}}+\mathrm{HPDF}$ stiffness of the coupled system (green line in Fig. 6), the stiffness of the dissipative system alone (1) is obtained as follows:

$$
\mathrm{K}_{-} \mathrm{HPDF}=\mathrm{K} \_ \text {(EX+HPDF) }-\mathrm{K}_{-} \mathrm{EX}
$$

The stiffness and strength properties of shear (S) and flexural (F) hinges are linked together and contribute to the global stiffness $\mathrm{K}_{\mathrm{HPDF}}$ according to equation (2).

As reported in [11] the contribution to the global stiffness and strength of $\mathrm{F}$ hinges is lower than that of S hinges which are usually more numerous. In some cases, the contribution of $F$ hinges could be also neglected by realizing a pinned connection at bottom end of the first story columns.

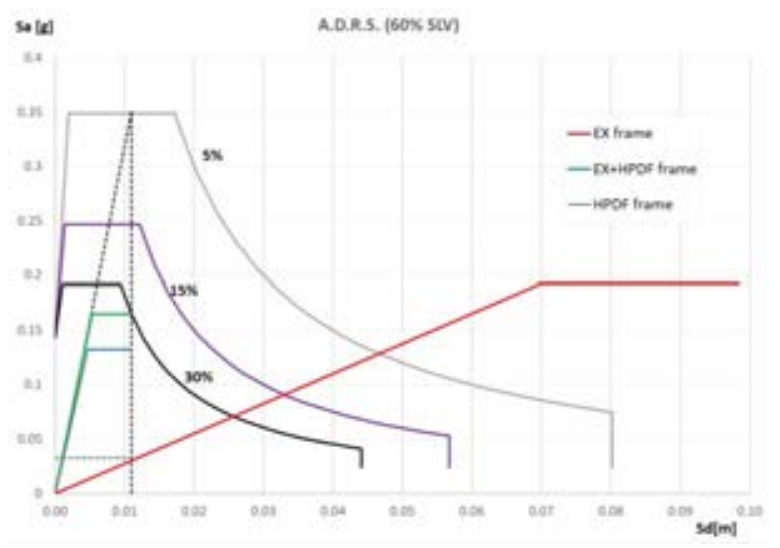

a)

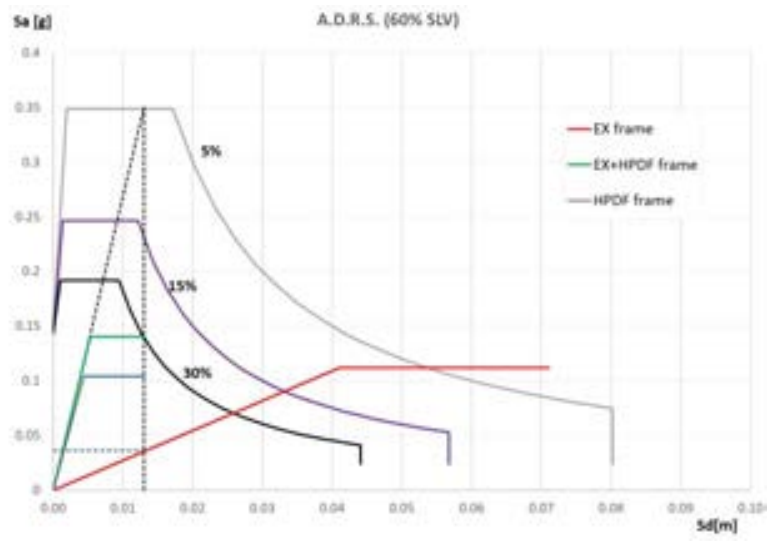

b)

Figure 6: Demand and capacity spectra according to ADRS format for x-direction a) and y-direction b). 


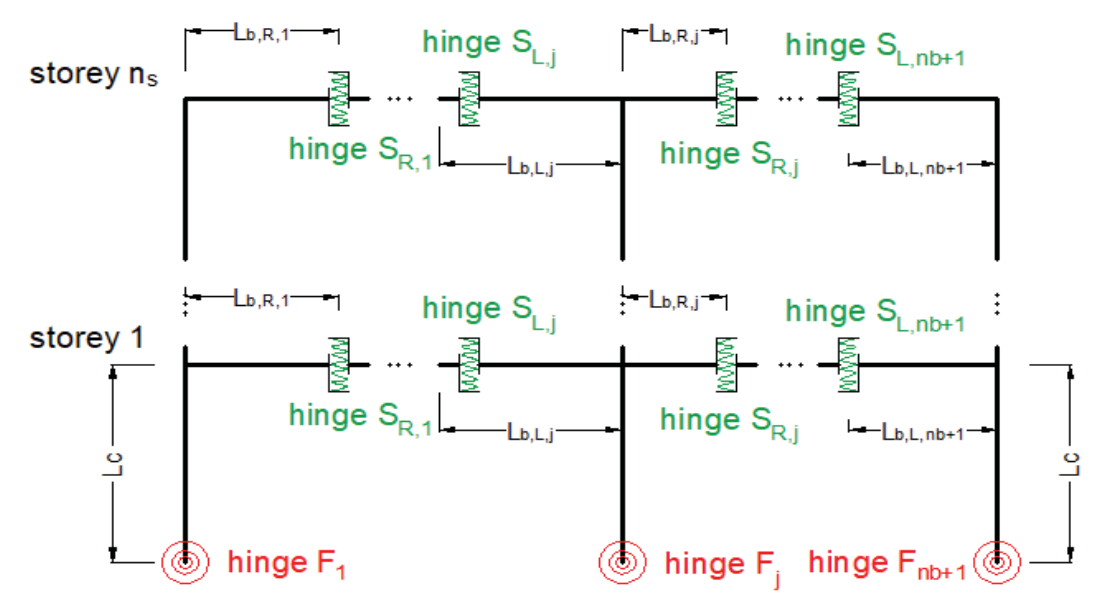

Figure 7: Stiffness of the dissipative system as a function of the stiffnesses of the individual devices in shear and bending.

$$
K_{H P D F, i}=\sum_{j=1}^{n_{b}+1} \frac{K_{F, j, i}}{n_{s}^{2} \cdot L_{c}^{2}}+2 \cdot \frac{K_{S L, i j} \cdot L_{b L, j, i}^{2}}{n_{s} \cdot L_{c}^{2}}+2 \cdot \frac{K_{S R, i j} \cdot L_{b R, j, i}^{2}}{n_{s} \cdot L_{c}^{2}}
$$

\subsection{Assessment of the upgraded structure}

The new HPDF frames are placed only externally, along the existing structure perimeter (Fig. 8). The upgraded structure is made of two RC frames working in parallel. New frames are devoted to subtracting seismic action from the existing ones in order to limit their stresses and deformations. However, frames along one side only work in their own plane, so their contribution is negligible in orthogonal direction. Therefore, post-intervention structural assessment can be made by means of separate PO analyses for the two plan directions.
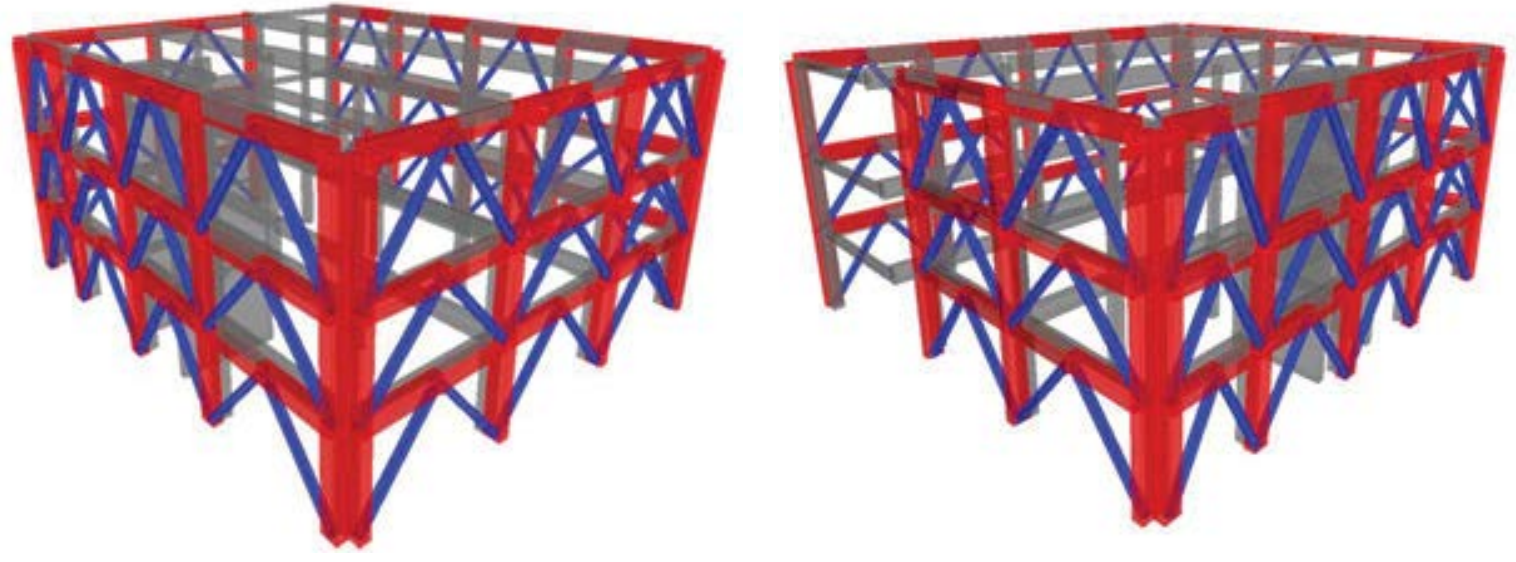

Figure 8: Exoskeleton defined by four HPDF frames.

The proposed methodology, which refers to the N2 method [17], is applied for each of the two main directions of analysis and is based on an iterative procedure [11]. That procedure allows the stiffness of dissipative elements to be calibrated according to the stiffness of the system (HPDF+existing structure) and the equivalent damping $\xi$. For each step of the analysis, the damping value must be compared to that one assumed, and to this purpose, the expression provided by Mazza and Vulcano [18] was adopted. Figure 6 shows the results in the final configuration at $30 \%$ damping. 
The first results showed that the flexural dampers provide a small contribution, so the frames were considered to have a pinned connection at the base. The characteristics of the shear dampers are shown in Figure 9.

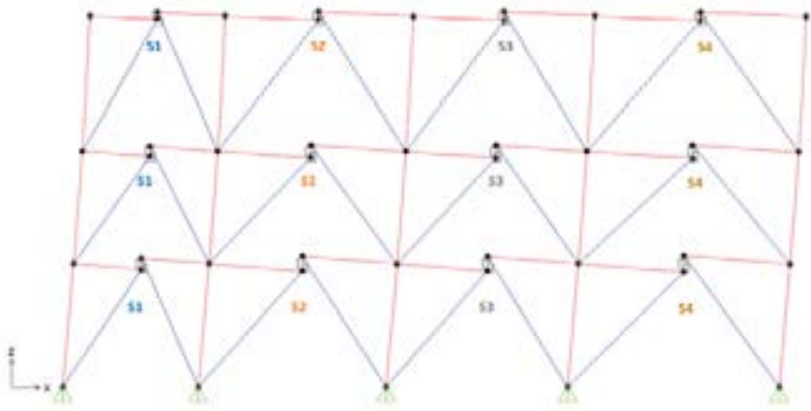

a)

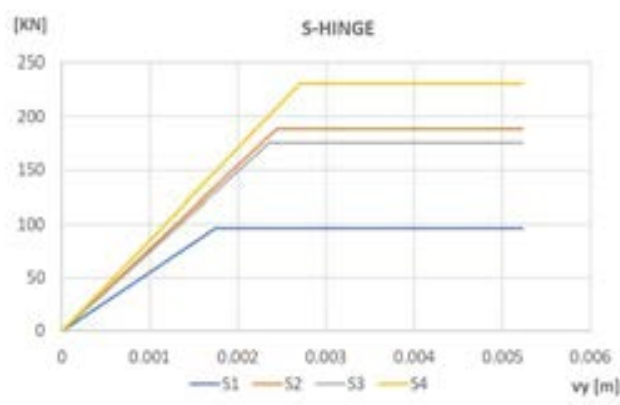

b)

Figure 9: Shear hinges on X frames a); Load-deformation relations of shear hinges b).

The four HPDF frames (Fig. 8) are defined by RC beam and column elements (concrete class $\mathrm{C} 28 / 35)$ with a $40 \times 60 \mathrm{~cm}$ rectangular cross-section. The braces are HEB300 and HEB240 steel profiles (structural steel of class S275), for the X-direction and Y-direction frames, respectively.

Figure 10 shows the capacity curves ante and post intervention for the $\mathrm{X}$ and $\mathrm{Y}$ plan directions. As can be seen, a large stiffness increase for both directions and a consequent increase in the base shear capacity at the target displacement are visible.

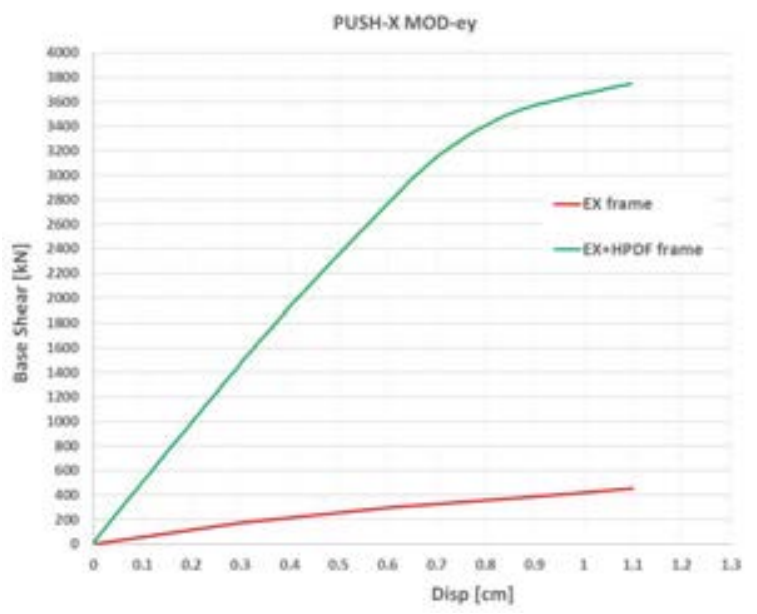

a)

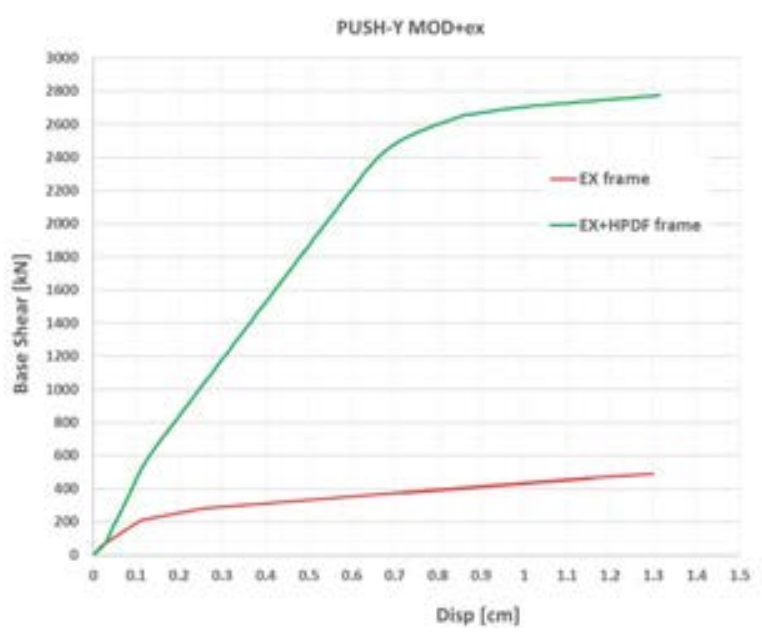

b)

Figure 10: Push-over pre and post intervention in $\mathrm{x}$-direction a) and y-direction $\mathrm{b}$ ).

Figure 11 shows the capacity-demand comparison in the ADSR format for the $\mathrm{X}$ and $\mathrm{Y}$ directions. As can be seen, a clearly larger stiffness is provided by the upgraded structure (HPDF + existing structure). The base shear has a higher value with respect to the assumption made in the design phase. This latter could be attributed to the existing structure irregularity that behave in a little different way when upgraded with the HPDF system, modifying the assumed distribution of base shear between the existing and the upgrading frames. However, this does not affect the effectiveness of the HPDF system, which relying on a $30 \%$ damping is able to lead the structure to the wanted performance displacement. 


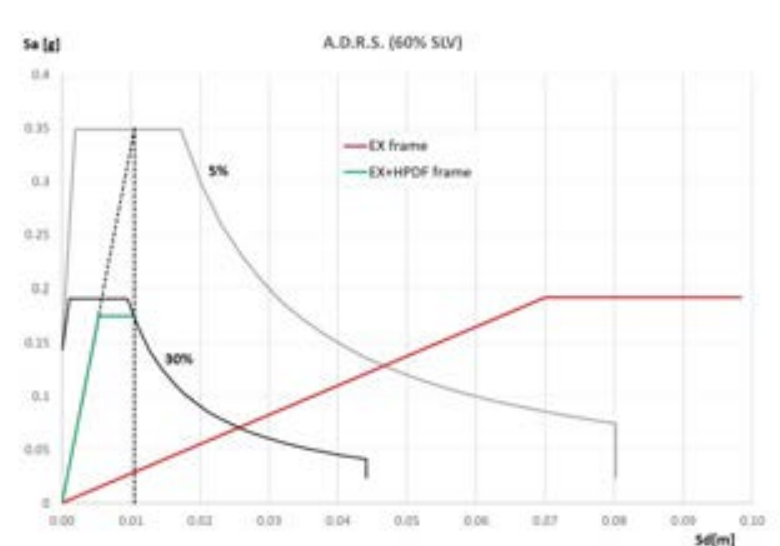

a)

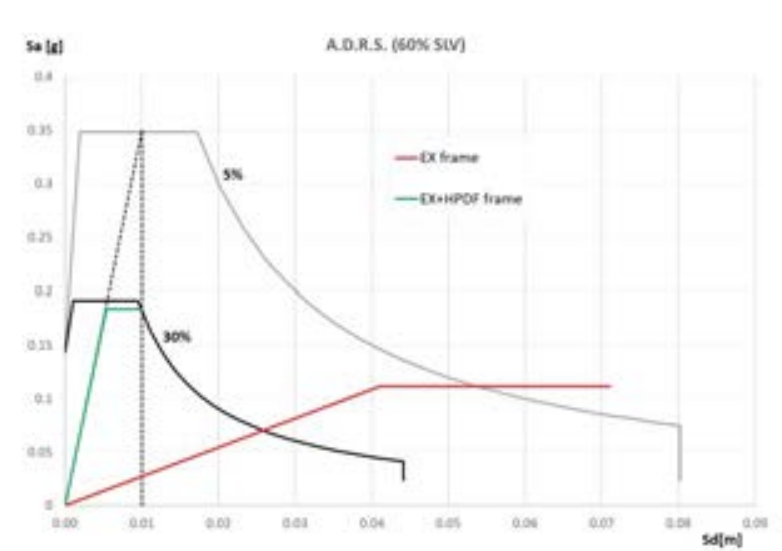

b)

Figure 11: Post-intervention structure capacity according to ADRS format in $\mathrm{x}$-direction a) and $\mathrm{y}$-direction $\mathrm{b}$ ).

\section{CONCLUSIONS}

Seismic strengthening techniques based on exoskeletons allow to operate only from the outside without interrupting the building use. Moreover, the demolition and restoration of nonstructural elements (e.g. plugging, flooring, infills, etc.) which cause considerable inconvenience to the occupants of the buildings is avoided.

The main aim of this study was to apply the HPDF system to a real case study building, which was so far developed and applied to simple structural schemes. The mentioned case study allowed to recognize that in case of large span length of the existing structures it appears advisable modifying the basic configuration adopted for the HPDF system. In fact, to increase the system effectiveness, it is suggested the installation of steel braces to reduce the beam and column deformability. This allows to fully exploit the relative displacement between beam ends, maximizing the global seismic performance. Moreover, in such a way, the $\mathrm{RC}$ members' cross section can be kept under dimensions more suitable from both the economic and aesthetic point of view.

The intervention was designed to upgrade the seismic capacity of the case study building that, in the as-built condition, was equal to $12 \%$ of the seismic demand $\left(\zeta_{\mathrm{E}}=0.12\right)$. The entire assessment process was performed in accordance to the current Italian seismic code with respect to the life safety limit state. The existing structure capacity is referred to the first fragile collapse and the upgrading system was designed to prevent it. This intervention approach favourably allows to apply only the HPDF system without any other local intervention to achieve the strengthening target.

Using an iterative design procedure, all the elements of the upgrading system were designed starting from the dissipative hinges up to the RC members and bracing steel members. The needed performance point was attained by providing a damping value of $30 \%$, which is usual for hysteretic devices like those used in the HPDF system.

The case study analysed in the present paper contributed to optimise the HPDF system for its application to real buildings showing the need of some layout modifications under the occurrence of specific structural configurations like, for example, the presence of long frame spans. 


\section{ACKNOWLEDGMENTS}

This study was partially developed under the financial support of the Italian Department of Civil Protection, within the ReLUIS-DPC 2019-2021 project, Research Line WP5. This support is gratefully acknowledged.

\section{REFERENCES}

[1] ISTAT. 2011: XV Censimento Generale della Popolazione e delle Abitazioni. Available online: www.istat.it.

[2] Santarsiero G., Masi, A. Key mechanisms of the seismic behaviour of external RC wide beam-column joints. Open Construction and Building Technology Journal. 13(1), pp. 36-51, 2019.

[3] Rossetto T., Peiris N., Alarcon J.E., So E., Sargeant S., Free M., Sword-Daniels V., Del Re D., Libberton C., Verrucci E., Field observations from the Aquila, Italy Earthquake of April 6, 2009. Bull Earthq Eng 9:11-37, 2011.

[4] Santarsiero G., Manfredi V. \& Masi, A. Numerical Evaluation of the Steel Plate Energy Absorption Device (SPEAD) for Seismic Strengthening of RC Frame Structures. Int $J$ Civ Eng 18, 835-850, 2020. https://doi.org/10.1007/s40999-020-00510-X.

[5] Labò S., Passoni C., Marini, A., Belleri A. Design of diagrid exoskeletons for the retrofit of existing RC buildings. Eng. Struct., 220, 110899, 2020.

[6] Di Lorenzo G., Colacurcio E., Di Filippo A., Formisano A., Massimilla A., Landolfo R., Steel exoskeletons for seismic retrofitting of existing reinforced concrete buildings: State-of-the art and a case study. XVIII ANIDIS Conference, Ascoli Piceno, Italy, 15-18 sept, 2019.

[7] Di Lorenzo G., Colacurcio E., Di Filippo A., Formisano A., Massimilla A., Landolfo R. State-of-the-art on steel exoskeletons for seismic retrofit of existing RC buildings. Ingegneria Sismica, 37(1):50, 2020.

[8] Del Vecchio C., Frascadore R., Menna C, Mauro G.M, Di Ludovico M, Di Sarno L, Bianco N., Prota A., Dolce M. An integrated design approach for the retrofit of existing RC school buildings, XVIII ANIDIS Conference, Ascoli Piceno, Italy, 15-18 Sept. 2019.

[9] Menna C., Del Vecchio C., Di Ludovico M., Mauro G.M., Ascione F., Prota A. Conceptual design of integrated seismic and energy retrofit interventions. Journal of Building Engineering, 38, 2021.

[10] Manfredi V., Masi A., Ventura G., Chiauzzi L., Digrisolo A., Santarsiero G., Rafforzamento sismico degli edifici esistenti in c.a. una soluzione innovativa per interventi integrati e sostenibili. Structural, 215 gennaio/febbraio. De Lettera Editore, 2018 (in Italian).

[11] Manfredi V., Santarsiero G., Masi A., Ventura, G., The High-Performance Dissipating Frame (HPDF) System for the Seismic Strengthening of RC Existing Buildings. Sustainability, 13, 1864, https://doi.org/10.3390/su13041864, 2021.

[12] Passoni C., Guo J., Christopoulos C., Marini A., Riva P. Design of dissipative and elastic high-strength exoskeleton solutions for sustainable seismic upgrades of existing RC buildings, Engineering Structures, Volume 221, 15 October 2020. 
[13] Ministero delle Infrastrutture, "NTC 2018-Decreto Ministeriale 17/1/2018 - Aggiornamento delle norme tecniche per le costruzioni".

[14] Masi A., Digrisolo A., Santarsiero G. Analysis of a large database of concrete core tests with emphasis on within-structure variability. Materials, 12(12),1985, 2019.

[15] Antoniou, S. Pinho R. Development and verification of a displacement-based adaptive pushover procedure. Journal of Earthquake Engineering 2004, 8:5, 643-661.

[16] Chopra A.K. Goel R.K. A modal pushover analysis procedure for estimating seismic demands for buildings. Earthquake Engineering and Structural Dynamics 2002, 31, 561582.

[17] Fajfar P. A nonlinear analysis method for performance based seismic design. Earthquake Spectra, 2000, Vol 16, No.3, pp 573-592, August 2000.

[18] Mazza F., Vulcano A. Displacement-based design procedure of damped braces for the seismic ret-rofitting of R.C. framed buildings. Bull Earthquake Eng 2015, 13, 2121-2143. 